\title{
Inviting new challenges
}

\author{
Julia Krout, MLAS, LATG, Manager of Logistics, Transportation and \\ Specialized Services, Memorial Sloan Kettering Cancer Center and \\ Weill Cornell Medical College, New York, NY.
}

Ms. Krout shares how she continually pushes herself to learn new things and talks about the importance of being involved in the laboratory animal community.

\section{You raised rabbits in 4- $\mathrm{H}$ growing up. Did this experience lead to your interest in laboratory animal science? It definitely did. I was always a huge animal lover; I was the stereotypical kid who said, "When I grow up, I want to be a vet." Through 4-H, I visited the Pennsylvania Department of Agriculture in high school. Seeing the veterinary pathologist at work there opened my eyes. I went home and searched the internet for laboratory animal science, and that interest has never left me.}

\section{What experiences do you think have helped you most in your career?}

I think I've been fortunate in my career that I've been able to see the whole picture of the laboratory animal field from many different angles. I worked as an animal care technician (ACT) while earning my Bachelor's degree, at two pharmaceutical companies prior to my graduate coursework and as an academic research assistant at Drexel University (Philadelphia, PA) while pursuing my Master's degree in Laboratory Animal Science. Because I have served in the roles of the ACT, the Principal Investigator (PI) and the colony manager, I've done everything from running experiments to participating in good laboratory practices studies and assisting in animal dosing and blood collection procedures. As a result, I understand the needs of the PIs, but also know how these needs may interfere with the work of the ACTs, and vice versa.

In the last few years, you've been working in the area of gnotobiotics. What is it that interests you about this field? What aspect of this work do you find the most challenging?

I have been blessed in that I have worked in many different areas of the laboratory animal science field, including gnotobiotics. I never thought I would do this work and honestly, it took me a few months to get truly excited about it. Once I did though, it became a new challenge for me. It is not part of the traditional idea of an animal facility. I think the most challenging aspect of it is how complex the work is. That's part of what makes it such an exciting opportunity. It allows me still to learn something new on a regular basisand I couldn't imagine life any other way.

You are very involved in the Metro New York branch of the American Association for Laboratory Animal Science (AALAS), receiving the Manager of the Year award in 2013 and acting as the Chair of Programs and Publicity for the upcoming 2014 AALAS Tribranch Symposium. Why is this work so important to you?

I have always been a busy person. I love to learn, and I love to share my passion with others. With 4-H, I tried to do every project and activity offered. I then volunteered and taught others as I became older. As time went on, my interest shifted from $4-\mathrm{H}$ and rabbits to laboratory animal science.

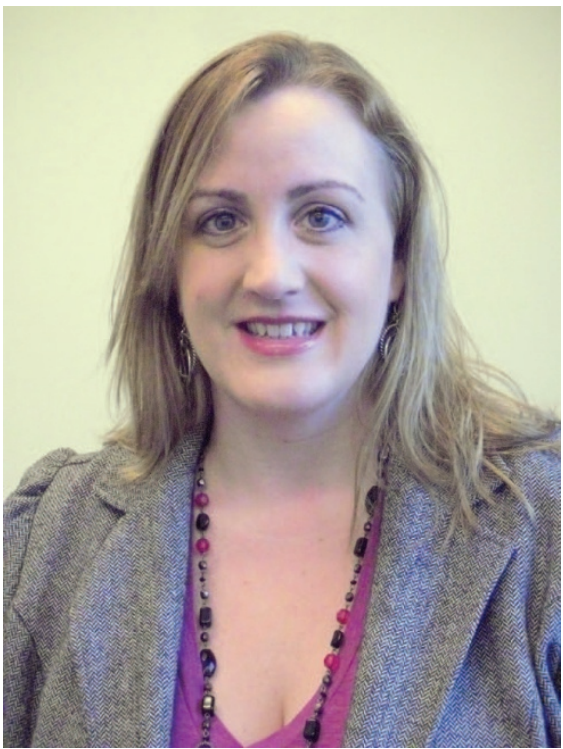

I love teaching and showing people how important the laboratory animal science field is. What we do matters, and we make a difference. I also believe those of us in this field always need to continue learning. I believe registering with AALAS to maintain the ' $\mathrm{R}$ ' in front of your ALAT, LAT and LATG certifications is important, and there should be many opportunities available for people to do this. Finally, I love to see what others are doing in the field and how they do it. Being involved in your local branch and your local conferences allows you to do that.

After working in the laboratory animal field for 11 years, do you have any remaining long-term career goals that you would like to share?

I am a self-professed geek. I became eligible for the Certified Manager of Animal Resources certification last summer, and I hope to add that to my list of certifications by March 2014. After that, I think I will start researching MBA programs or take online certificate courses dealing with laboratory animal science. Like I said before, I love to learn and I never want to stop! 